\title{
Sexually dimorphic role for vasopressin in the development of social play
}

\section{Matthew J. Paul ${ }^{*}$, Joseph I. Terranova ${ }^{1}$, Clemens K. Probst ${ }^{2}$, Elaine K. Murray ${ }^{3}$, Nafissa I. Ismail $^{4}$ and Geert J. de Vries $^{1}$}

${ }^{1}$ Neuroscience Institute, Georgia State University, Atlanta, GA, USA

${ }^{2}$ Center for Neuroendocrine Studies, University of Massachusetts, Amherst, MA, USA

${ }^{3}$ Northern Ireland Centre for Stratified Medicine, University of UIster, UIster, UK

${ }^{4}$ School of Psychology, University of Ottawa, Ottawa, ON, Canada

\section{Edited by:}

Regina M. Sullivan, Nathan Kline Institute and NYU School of Medicine, USA

\section{Reviewed by:}

Karen L. Bales, University of California Davis, USA

Craig F. Ferris, Northeastern

University, USA

*Correspondence:

Matthew J. Paul, Neuroscience Institute, Georgia State University,

P. O. Box 5030, Atlanta, GA

30302-5030, USA

e-mail:mpaul@gsu.edu
Despite the well-established role of arginine vasopressin (AVP) in adult social behavior, its role in social development is relatively unexplored. In this paper, we focus on the most prominent social behavior of juvenile rats, social play. Previous pharmacological experiments in our laboratory suggested that AVP regulates play in a sex- and brain region-specific manner in juvenile rats. Here we investigate the role of specific AVP systems in the emergence of social play. We first characterize the development of play in male and female Wistar rats and then ask whether the development of AVP mRNA expression correlates with the emergence of play. Unexpectedly, play emerged more rapidly in weanling-aged females than in males, resulting in a sex difference opposite of that typically reported for older, juvenile rats. AVP mRNA and play were correlated in males only, with a negative correlation in the bed nucleus of the stria terminalis (BNST) and a positive correlation in the paraventricular nucleus of the hypothalamus (PVN). These findings support the hypothesis that AVP acts differentially on multiple systems in a sex-specific manner to regulate social play and suggest a role for PVN and BNST AVP systems in the development of play. Differential neuropeptide regulation of male and female social development may underlie well-documented sex differences in incidence, progression, and symptom severity of behavioral disorders during development.

Keywords: play fighting, social behavior, bed nucleus of the stria terminalis, paraventricular nucleus of the hypothalamus, juvenile, weanling, sex differences

\section{INTRODUCTION}

Many neurodevelopmental disorders exhibit sex differences in incidence, progression, and symptom severity (Fombonne, 2009; Abel et al., 2010). This is particularly striking among disorders affecting social development such as autism spectrum disorders (ASD) and attention deficit hyperactivity disorder (ADHD), which are much more common in boys than in girls (reviewed in Rutter et al., 2003). Sex differences in neurobiological mechanisms that influence social development likely contribute to this differential vulnerability. Unfortunately, our understanding of these mechanisms is quite poor.

Social play contributes to the development of adult social and emotional skills (Pellegrini, 1988; Vanderschuren et al., 1997; Hol et al., 1999; Van den Berg et al., 1999) and is ideal for studying the neurobiology of social development. Notably, deficits in social play have been associated with ASD, ADHD, and schizophrenia (Alessandri, 1992; Jones et al., 1994; Jordan, 2003). The most common form of social play is play fighting, where participants engage in rough-and-tumble behaviors that resemble light-hearted wrestling (Bekoff and Byers, 1998). Play fighting in rats emerges around 18 days of age, peaks at 30-40 days of age, and declines thereafter (Panksepp, 1981). At its peak, males typically play more than females (Olioff and Stewart, 1978; Pellis et al., 1997), making play particularly valuable for studying sex differences in social development.

The neuropeptide arginine vasopressin (AVP) has been implicated in a number of adult social behaviors (reviewed in Caldwell et al., 2008). AVP may play an equally important role in social behavior during adolescence. Studies in our and other laboratories have demonstrated that AVP 1a receptor (V1aR) antagonists influence levels of play fighting in juvenile hamsters and rats (Cheng and Delville, 2009; Veenema et al., 2013), but the direction of these effects depends upon the sex of the subject and brain area injected. For example, intracerebroventricular injections of a V1aR antagonist decrease play fighting of male rats, but increase that of females, whereas septal injections cause the opposite effects (Veenema et al., 2013). It is not clear, however, which systems are responsible for AVP's actions on social play.

AVP neurons in the bed nucleus of the stria terminalis (BNST) and paraventricular nucleus of the hypothalamus (PVN) are candidate sources for AVP's actions on play. The lateral septum receives projections from the BNST (De Vries and Buijs, 1983), a primary node in the neural network thought to play a role in social behavior (Newman, 1999). Furthermore, AVP cells within 
this nucleus are sensitive to sex steroids and exhibit the most consistent sexual dimorphism found across vertebrates, with more cells in males than in females (De Vries and Panzica, 2006). In the PVN, AVP mRNA expression is altered by experimental manipulations that impact agonistic and affiliative interactions, including play (Veenema et al., 2006; Veenema and Neumann, 2009; Murakami et al., 2011; De Souza et al., 2013).

In the present study, we used a developmental paradigm to investigate a potential role for BNST and PVN AVP systems in the regulation of play. Hence, in a preliminary experiment, we characterized the development of play behavior in male and female Wistar rats. In a subsequent experiment, we tested whether the development of AVP mRNA expression in the BNST and PVN correlates with play's emergence. Based on our previous psychopharmacological data, we predicted that the development of AVP expression in the BNST and PVN would correlate with the emergence of play behavior in sexually dimorphic and regionspecific ways. As this was indeed the case, our data suggest distinct and sexually dimorphic roles for AVP cells in the BNST and PVN in play development. They also reveal a novel sex difference in the emergence of play.

\section{MATERIALS AND METHODS ANIMALS AND HOUSING CONDITIONS}

Wistar rats were purchased from Charles River Laboratories and housed in opaque plastic cages $(48 \times 27 \times 20 \mathrm{~cm})$ with Carefresh bedding and wood chips. Rats that arrived prior to weaning were housed with their mother and siblings. For all experiments, the day of birth was considered postnatal day 0. Room lights were set to a 12:12 light:dark cycle (lights off at 17:00 h ET), and ambient temperature was maintained at $23^{\circ} \mathrm{C}$. Food and water were available ad libitum. All procedures were in accordance with the Guide for Care and Use of Laboratory Animals and were approved by the Animal Care and Use Committee at the University of Massachusetts, Amherst.

\section{EXPERIMENTAL PROCEDURES}

\section{Experiment 1a: emergence of play behavior}

Pups arrived between 7-14 days of age with their mother and siblings (10 pups/litter consisting of 5 males and 5 females). Each pup was tested for play behavior once at 16, 19, 21, or 24 days of age. Testing each animal only one time ensured that effects seen in the current study were due to developmental changes rather than experience of repeated testing. Weanling-aged rats were removed from their litters and single-housed for 30-60 min before being paired with a similarly treated age-matched, same-sex rat in a clean cage for play testing. Two randomly selected animals in each litter ( 1 male and 1 female) were not tested. Sample sizes were $n=4$ play pairs for all groups. One video of an 18 -day-old female play pair was out of focus and could not be scored, reducing the sample size to $n=3$ in this group.

\section{Experiment 1b: play behavior of juveniles}

To determine whether the sex differences in play emergence persist into the juvenile phase, a second set of rats treated identically to those in Experiment 1a were tested for play behavior at 3536 days of age. Pups arrived between 7-14 days of age with their mother and siblings (10 pups/litter of 5 males and 5 females). Again, two randomly selected animals in each litter ( 1 male and 1 female) were not tested. Sample sizes were $n=4$ per group.

\section{Experiment 2: arginine vasopressin (AVP) expression during the emergence of play}

Pups arrived between 7-14 days of age with their mother and siblings (10 pups/litter consisting of 5 males and 5 females). Each pup was tested for play behavior once at 18, 19, 20, or 21 days of age. To ensure that pups were paired with a motivated playmate and that their play behavior was not suppressed by an unwilling partner, each weanling-aged rat was tested with a juvenile (35 days of age) of the same-sex that had been single-housed for $24 \mathrm{~h}$ before testing; in rats, play peaks around 30-40 days of age, and $24 \mathrm{~h}$ of isolation further stimulates play (Panksepp, 1981). Pairing weanlings with a motivated juvenile stimulus rat also removed the need to isolate the experimental weanlings prior to the play test, a procedure that would confound measures of AVP expression. Weanling-aged rats were taken directly from their litters and placed in the juvenile's home cage. Sample sizes were $n=8$ for male and female 18-day-old rats, $n=7$ for male and female 19day-old rats, $n=4$ for male and female 20-day-old rats, $n=5$ for male 21-day-old rats, and $n=4$ for female 21-day-old rats. At the end of the 30-min play test, a subset of weanling-aged rats was sacrificed under red light by $\mathrm{CO}_{2}$ inhalation $(n=5$ for 18-day-old females, 18-day-old males, and 21-day-old males; $n=4$ for 21-day-old females). Brains were removed, immediately frozen in 2-methylbutane that was kept on dry ice, and stored at $-80^{\circ} \mathrm{C}$ until processed by in situ hybridization for AVP mRNA expression.

\section{PLAY BEHAVIOR TESTS}

All play tests were conducted within the first $2.5 \mathrm{~h}$ of lights off under red light. Animals were paired with a same-sex playmate in similar cages as used for housing. Each play session lasted for $30 \mathrm{~min}$, during which behaviors were recorded using the nightshot setting on a Sony Handycam video camera (DCRSR85). The number of pounces (lunges toward the nape of the playmate's neck), pins (animal on top, holding playmate in a supine position), and boxing events (both animals standing on their hind paws and pushing each other with their forepaws), as described in Meaney and Stewart (1981b) and Vanderschuren et al. (1997), were scored by a researcher blind to the treatment conditions using JWatcher software. ${ }^{1}$

\section{ARGININE VASOPRESSIN (AVP) IN SITU HYBRIDIZATION AND ANALYSIS}

Brains collected from weanling-aged rats were cut on a cryostat into $20 \mu \mathrm{m}$ thick coronal sections, thaw-mounted onto Superfrost/plus slides (Thermo Fisher Scientific, Pittsburgh, $\mathrm{PA})$, and stored at $-80^{\circ} \mathrm{C}$. Every third section was processed for AVP in situ hybridization. These sections were postfixed in $4 \%$ paraformaldehyde at $4^{\circ} \mathrm{C}$ for $15 \mathrm{~min}$ and then rinsed in the following buffers: (1) $0.1 \mathrm{M}$ phosphate-buffered saline ( $\mathrm{pH} 7.4$ ) for $2 \mathrm{~min}$ at $4^{\circ} \mathrm{C}$; (2) $0.1 \mathrm{M}$ triethanolamine buffer

\footnotetext{
${ }^{1}$ http://www.jwatcher.ucla.edu/
} 
$(\mathrm{pH} 8.0)$ for $1 \mathrm{~min}$ at room temperature (remainder of rinses were done at room temperature); (3) $0.1 \mathrm{M}$ triethanolamine buffer ( $\mathrm{pH}$ 8.0) with $2.5 \mu \mathrm{l} / \mathrm{ml}$ acetic anhydride for $10 \mathrm{~min}$; (4) $2 \mathrm{X}$ standard sodium citrate (SSC) buffer (0.3 M sodium chloride and $0.03 \mathrm{M}$ sodium citrate in distilled water, $\mathrm{pH} 7.0$ ) for $1 \mathrm{~min}$; (5) $70 \%$ ethanol for $2 \mathrm{~min}$; (6) $100 \%$ ethanol for $2 \mathrm{~min}$; (7) chloroform for $5 \mathrm{~min}$; and (8) 100\% ethanol for $2 \mathrm{~min}$. In situ hybridization was carried out using a mixture of two oligodeoxyribose antisense probes. Probe 1: $5^{\prime}$-CAGCTGGCTG GGACACAAGAGTCCGTGGATTCTGCCAAGCCCCGGGTC-3' Probe 2: 5'-CCGCGCTCGGGAGCAGAGCAACGCCACGCAGC TGGACGG- $3^{\prime}$. Probes were labeled at the $3^{\prime}$ end with ${ }^{35}$ S-dATP (PerkinElmer, Waltham, MA) using terminal deoxynucleotidyl transferase (T4427, Sigma, Saint Louis, MI) and terminal transferase buffer (B0315S, New England BioLabs, Ipswich, MA). For hybridization, $100 \mu \mathrm{l}$ of ${ }^{35} \mathrm{~S}$-labeled probe in hybridization buffer (50\% formamide, $10 \%$ dextran sulfate, $0.3 \mathrm{M} \mathrm{NaCl}, 10 \mathrm{mM}$ Tris, $1 \mathrm{mM}$ EDTA, 1X Denhardt's solution, $10 \mathrm{mM}$ dithiothreitol) was added to each slide. Slides were then coverslipped and incubated at $37^{\circ} \mathrm{C}$ overnight. All solutions for the pre-hybridization steps were made with Diethylpyrocarbonate (DEPC)-treated water. Following hybridization, coverslips and hybridization buffer were removed by dipping in $1 \mathrm{X}$ SSC at room temperature. Slides were rinsed in $1 \mathrm{X} \mathrm{SSC}$ for $4 \times 15 \mathrm{~min}$ at $55^{\circ} \mathrm{C}$. Subsequent rinses were done at room temperature in the following order: (1) 1X SSC for $15 \mathrm{~min}$; (2) 1 X SSC for $2 \times 45 \mathrm{~min}$; (3) 70\% ethanol for $2 \mathrm{~min}$; (4) $95 \%$ ethanol for $2 \mathrm{~min}$; and (5) 100\% ethanol for $2 \mathrm{~min}$.

Hybridization signal was visualized using two methods. First, slides were exposed to film. Second, slides were dipped in emulsion (NTB2, Kodak, Rochester, NY) at $42^{\circ} \mathrm{C}$ under safelight and stored at $4^{\circ} \mathrm{C}$ in light tight boxes containing desiccant capsules. Slides were developed under safelight in the following solutions: (1) Dektol-19 developer (1:1 with purified water) for $2 \mathrm{~min}$ at $15^{\circ} \mathrm{C}$; (2) distilled water for $30 \mathrm{~s}$; (3) fixative (Kodak) for $5 \mathrm{~min}$; and (4) distilled water for $5 \mathrm{~min}$. Slides were then rinsed in running water for $3 \mathrm{~min}$, lightly counterstained with $2 \%$ methyl green for $30 \mathrm{~s}$, rinsed with running water until clear, dehydrated in 50\% ethanol, and coverslipped with Cytoseal 60 (Richard-Allen Scientific, Kalamazoo, MI).

AVP mRNA expression in the BNST and PVN was analyzed using the exposed film. The film was placed on a lightbox and the full rostro-caudal extent of each nucleus was photographed. Radioactive label, indicating the presence of AVP mRNA, was quantified as the number of pixels above background using the threshold function of ImageJ software (NIH, Bethesda, MD) and summed for all sections containing the BNST or PVN. The radioactive signal from AVP expression in the PVN was much greater than that in the BNST, and appeared overexposed in the majority of cases. Therefore, AVP expression in the PVN was also quantified from the emulsion-dipped slides; BNST AVP expression was not quantified using this method because the clusters of silver grains in this nucleus were difficult to detect above background in the weanling-aged rats. The full rostro-caudal extent of the PVN on the right side of the brain was photographed using a SPOT camera and software on a Nikon Eclipse E6200 microscope. Several pictures were often needed to capture the entire PVN at this magnification. These pictures were assembled into a single TIFF file using Adobe Photoshop. Radioactive label was quantified as the number of pixels above background using NIH ImageJ and summed for all sections containing the PVN.

\section{DATA ANALYSIS}

Play behavior and AVP expression were analyzed using a two-way ANOVA or Student's $t$-test. Post-hoc comparisons were conducted using Fisher's PLSD only when the overall ANOVA was significant. Correlations between play behavior and AVP expression were assessed by simple regression analysis. For play behavior, the number of pounces, pins, and boxing events were analyzed separately and combined as the sum total of play behaviors that occurred during the play session (Total Play Score). The unit of analysis was the pair. Therefore, a single score was provided for each age-matched pair in Experiment $1 \mathrm{a}$ and b, and only the behavior of the weanling-aged rat was considered in Experiment 2 (behavior of juvenile stimulus animal was not included in the analyses). This yielded play scores derived from differing numbers of individuals: two rats per play pair in Experiment 1a and b, but only one rat in Experiment 2-because behavior of juvenile rats was not included in analyses. Therefore, scores from Experiment $1 \mathrm{a}$ and $\mathrm{b}$ were converted to the mean number of behaviors per playmate to normalize play scores across experiments. All statistical analyses were conducted using Statview 5.0.1 (SAS Institute, Cary, NC). Significance was assumed if $P<0.05$.

\section{RESULTS}

\section{EXPERIMENT 1A: EMERGENCE OF PLAY BEHAVIOR}

Female weanling-aged rats exhibited a more rapid emergence of pinning behavior than males (Figure 1A) resulting in a sex difference opposite that typically reported for juveniles (e.g., Krebs-Kraft et al., 2010). Overall, females displayed more Pins than did males (main effect of sex, $P<0.03$, two-way ANOVA). The number of Pins increased across age (main effect of age, $P<$ 0.002 , two-way ANOVA), but only in females (interaction, $P<$ 0.04, two-way ANOVA). At 24 days of age, females displayed more Pins than did males $(P<0.0009$, Fisher's PLSD). Total Play (data not shown) and Pounces (Figure 1C) increased across age (main effect of age, $P<0.005$ for both measures, two-way ANOVA). However, there was no effect of sex and the interaction was not significant ( $P>0.05$ for both measures, two-way ANOVA). Boxing was low and did not differ across age or between sex (age, sex, interaction, $P>0.05$; two-way ANOVA; data not shown).

\section{EXPERIMENT 1B: PLAY BEHAVIOR OF JUVENILES}

The higher levels of pinning seen in female weanlings compared to male weanlings did not persist into the juvenile stage of development. There were no differences in Total Play, Pins, Pounces, or Boxing between male and female juvenile rats $(P>0.32$ for all measures, Student's $t$-test; Figures 1B, D; Total Play and Boxing data not shown).

\section{EXPERIMENT 2: ARGININE VASOPRESSIN (AVP) EXPRESSION DURING THE EMERGENCE OF PLAY \\ Play behavior}

Both weanlings and juveniles exhibited the characteristic play behaviors in their natural forms. Only levels of Pins were affected 

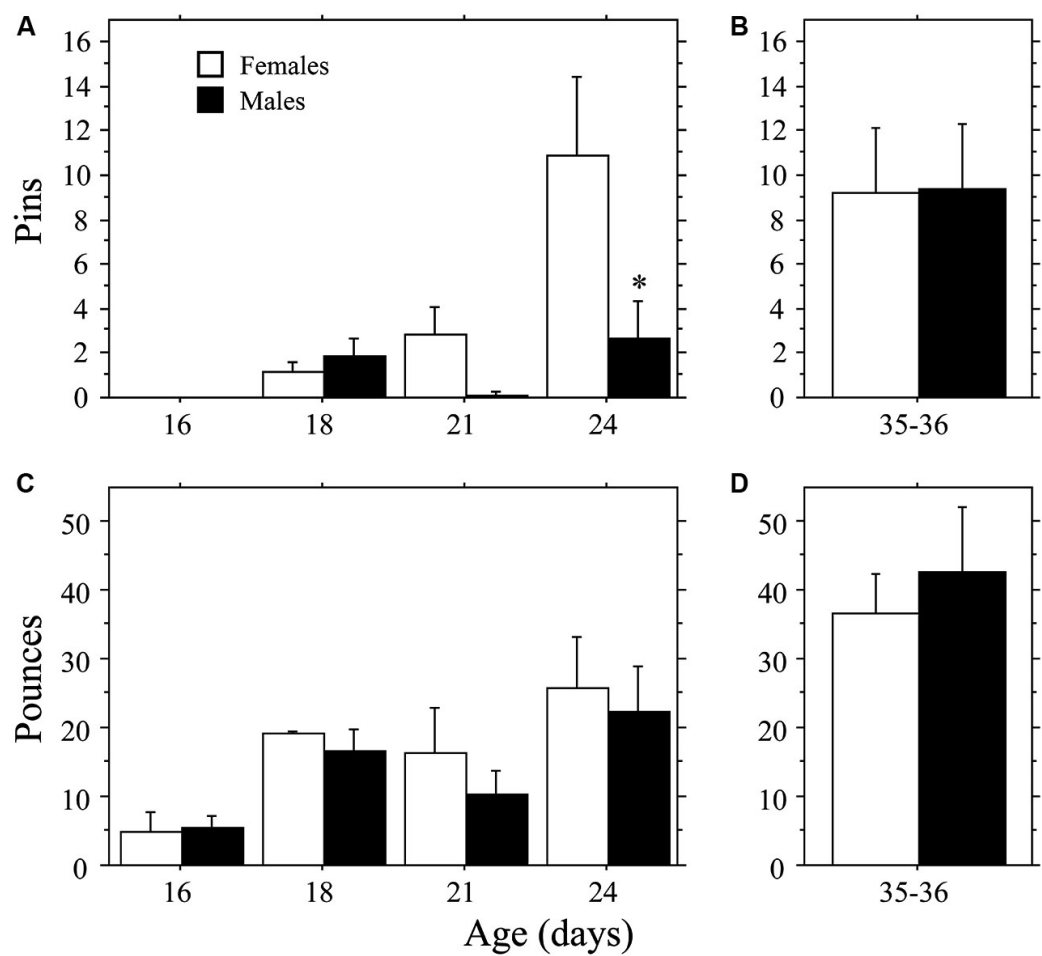

FIGURE 1 | Development of play behavior in female and male age-matched rat pairs. Mean number (+s.e.m.) of pins (A and $\mathbf{B})$ and pounces (C and $\mathbf{D})$ per playmate in weanling (A and $\mathbf{C}$; Experiment 1a) and juvenile (B and $\mathbf{D}$; Experiment 1b) play pairs; * indicates significant sex difference within age group.

by the differing ages of the playmates, which were variable and low in number in the weanlings. Similar to that seen in Experiment 1a, play emerged more rapidly in females than in males. This time, however, the effect was stronger for Total Play and Pounces than it was for Pins, which appeared to be hindered by the large body size of the juvenile stimulus playmate. No main effects or interaction were seen for Pins (main effect of age, $P>0.4$; main effect of sex, $P>0.09$; interaction, $P>0.60$, two-way ANOVA; Figure 2). Female weanlings exhibited higher levels of Total Play and Pounces than did males (main effect of sex, $P<0.002$ for both measures, two-way ANOVA; Figure 2). There was an overall increase in Total Play, Pounces, and Boxing events across age (main effect of age, $P<0.008$ for all 3 measures, two-way ANOVA). Only females exhibited striking increases in Total Play, Pounces, and Boxing events between 18 and 19 days of age $(P<$ 0.001 for all 3 measures, Fisher's PLSD), which led to significantly higher levels in females compared to males at this age $(P<0.002$ for all 3 measures, Fisher's PLSD). While Pins displayed the same pattern, the overall ANOVA was not significant, prohibiting posthoc comparisons. For males, play behaviors failed to significantly rise above day 18 values throughout the test period (day 18-21; $P>0.05$ for Total Play, Pounces, and Boxing, Fisher's PLSD).

\section{Arginine vasopressin (AVP) expression at 18 and 21 days of age}

Figure 3 contains representative pictures of the AVP in situ hybridization in the BNST (panel A) and PVN (panel E). As expected, AVP mRNA expression in the BNST of weanling aged-rats was much higher in males than in females (main effect of sex, $P<0.0001$, two-way ANOVA; Figure 3B). AVP mRNA varied across age (main effect of age, $P<0.04$, two-way ANOVA) in a sex-specific manner (interaction, $P<0.04$, two-way ANOVA). Specifically, expression declined in males between 18 and 21 days of age $(P<0.004$, Fisher's PLSD), but did not change in females $(P>0.99$, Fisher's PLSD). Thus, as play increased across development, AVP expression in the BNST of males decreased. To determine whether AVP mRNA levels were related to individual variations in play, we determined whether there was a correlation between the AVP expression of individual animals and their Total Play scores. We first examined both ages combined. Not surprisingly, the consistently low levels of BNST AVP expression in females was not correlated with Total Play $(P>0.28$, Regression; Figure $3 \mathrm{C}$ ). In males, however, there was a significant negative correlation between these variables that accounted for $71 \%$ of the variance $\left(P<0.003, R^{2}=0.71\right.$, Regression; Figure 3D). Notably, this negative correlation remained significant when the analysis was restricted to 18-day-old male rats even though the sample size was small ( $n=5 ; P<0.05, R^{2}=0.78$, Regression); for 21 day-old males, the correlation fell short of significance $(P=0.16$, Regression).

In contrast to the BNST, the PVN showed similar AVP expression between males and females, which did not vary significantly with age (main effect of sex, $P>0.4$; main effect of age, $P>$ 0.11 ; interaction, $P>0.98$, two-way ANOVA; Figure 3F). AVP expression in the PVN of females was not significantly correlated with Total Play scores $(P>0.58$, Regression; Figure 3G). In males, however, AVP expression in the PVN was positively correlated 
A

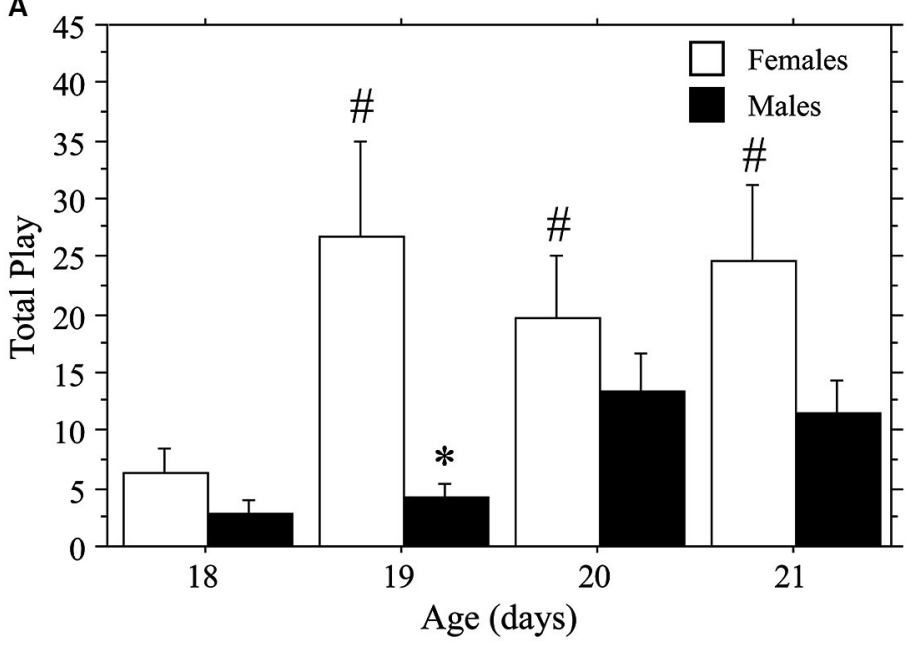

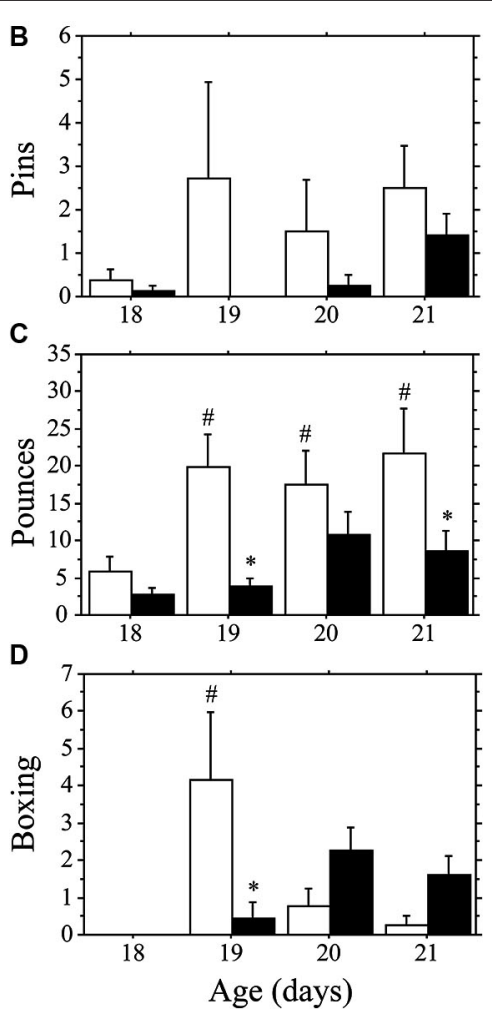

FIGURE 2 | Play emerges more rapidly in female than in male rats. Mean number (+s.e.m.) of all play behaviors (A), pins (B), pounces (C), and boxing events (D) in weanling-aged females (open bars) and males (closed bars) paired with 35-day-old juvenile play partners; * indicates significant sex difference within age group; \# indicates significant increase above day 18 baseline measure for females. with Total Play $\left(P<0.04, R^{2}=0.43\right.$, Regression; Figure $\left.3 \mathrm{H}\right)$. The correlation was not significant when restricted to only 18 - or 21day-old males (Day 18, $P=0.07$; Day 21, $P>0.62$, Regression).

\section{DISCUSSIONS}

While AVP has been implicated in juvenile social play (Cheng and Delville, 2009; Veenema et al., 2013), the circuits through which AVP influences play are not known. Here we assessed AVP expression in the PVN and BNST during the emergence of social play in rats and found sex- and region-specific correlations between AVP mRNA expression and play behavior. These data are consistent with opposing roles for AVP neurons in the PVN and BNST in the regulation of play in males and suggest how AVP systems might interact to regulate the development of play in a sexually dimorphic manner.

As play behavior develops, AVP mRNA expression in the BNST of males declined, suggesting an inhibitory role for AVP in this nucleus. Indeed, we found a striking negative correlation between BNST AVP mRNA and play behavior in males. These data are consistent with our earlier observation that play behavior is increased in juvenile male rats infused with a V1aR antagonist into the septum (Veenema et al., 2013) and identify the BNST as the likely source of AVP's inhibitory actions in the septum of males. In that same study, intracerebroventricular infusions of this $\mathrm{VlaR}$ antagonist, which reach a much wider range of potential neural AVP targets, reduced play in males. This suggests that AVP acts on multiple systems, with both stimulatory and inhibitory actions on play. Our data point to the PVN as a potential source of the stimulatory effect, as AVP mRNA in the PVN correlated positively with Total Play in males. This finding is also consistent with increased PVN AVP mRNA expression that accompanies enhanced offensive play behaviors in juvenile male rats after early postnatal maternal separation (Veenema and Neumann, 2009). Our findings could reflect regulation of AVP expression by development, the environment, or both. Weanlings were sacrificed $30 \mathrm{~min}$ after introduction to an unfamiliar 35-dayold juvenile, which might be sufficient time for environmental factors to alter AVP mRNA-restraint stress increases AVP mRNA in the PVN within 15 min (Dent et al., 2000). Nonetheless, our findings when considered with those discussed above suggest that different AVP systems have distinct influences on male play early in development, perhaps with BNST and PVN AVP systems opposing each other.

We did not detect a correlation between play and AVP mRNA in either the BNST or PVN of female rats. Nonetheless, AVP does influence play in this sex, at least during the juvenile phase, as infusions of a $\mathrm{V} 1 \mathrm{aR}$ antagonist alter levels of play in females, again in a region-specific manner (Veenema et al., 2013). Effects of these infusions, however, are opposite to those seen in males. Hence, AVP influences play in males and females through distinct mechanisms, which might explain why we did not find significant correlations in females. AVP may act via other nuclei 


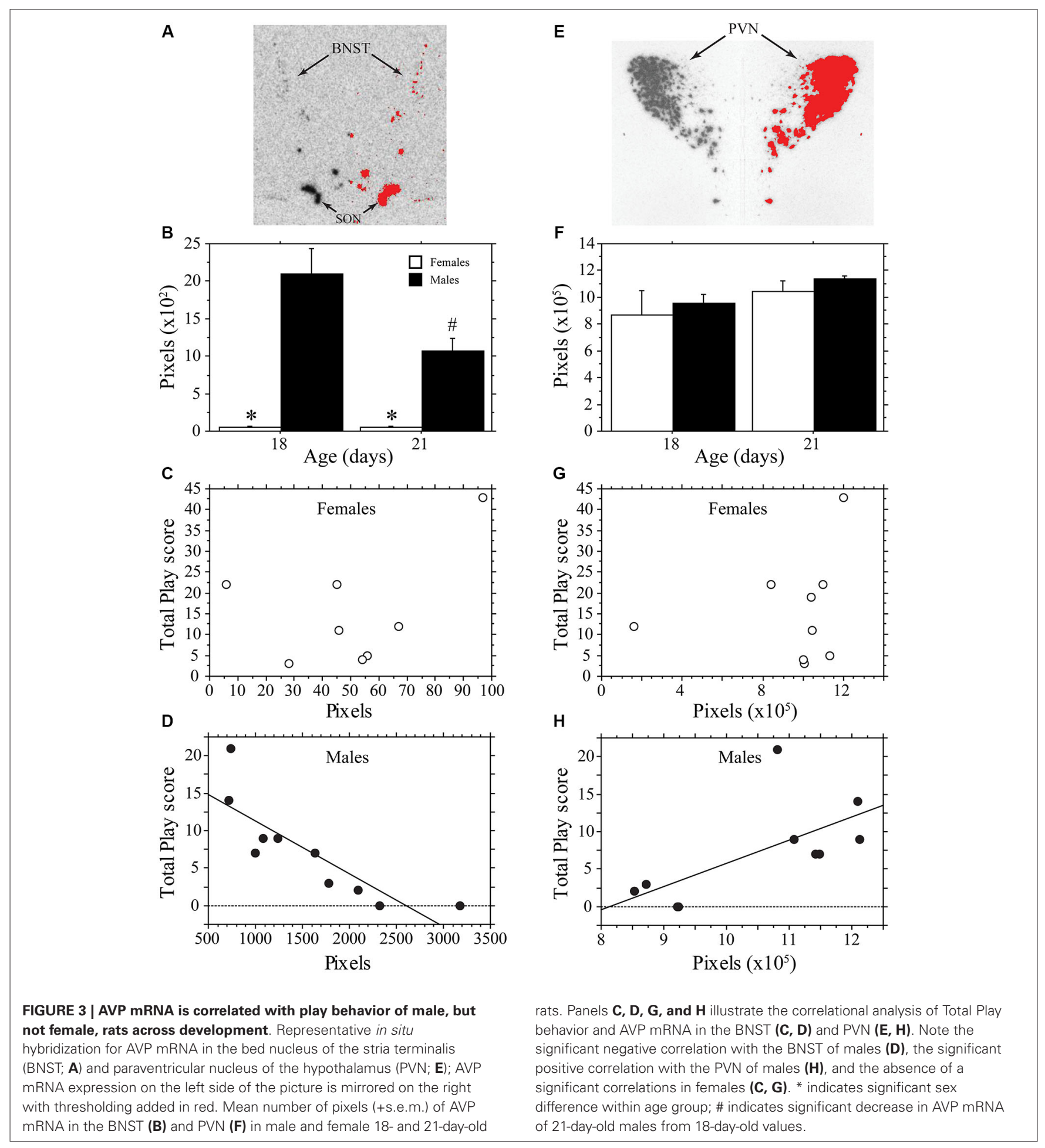

not considered in the present study that likely contribute to AVP's actions on play, e.g., nucleus circularis, supraoptic nucleus, medial amygdaloid nucleus (Cheng et al., 2008; Kurian et al., 2008; Forbes-Lorman et al., 2012). Alternatively, AVP's actions in females may be regulated at a different stage (e.g., peptide production or secretion). Given the high level of AVP expression in the PVN, it remains possible that AVP's actions on play behavior in

females are mediated through a subset of PVN cells (e.g., centrally projecting parvocellular cells; Sawchenko and Swanson, 1982) in which mRNA differences might be obscured when the PVN is analyzed as a whole.

As in previous studies, play first emerged around 18-19 days of age (Bolles and Woods, 1964; Panksepp, 1981; Thiels et al., 1990). Unexpectedly, play emerged more rapidly in females than 
in males, resulting in a sex difference (females $>$ males) counter to that traditionally reported in juvenile rats (e.g., Meaney and Stewart, 1981b). This "reversed" sex difference did not persist beyond the weanling period, as sex differences were not detected in the 35-day-old juvenile rats tested under the same conditions (Figure 1). These data suggest that sex differences in play depend on the developmental stage at which animals are tested. Environmental factors are also likely to affect sex differences in play emergence. Detection of sex differences in play is highly sensitive to environmental conditions (Thor and Holloway, 1984). While males are consistently found to play more than females when tested in mix-sex groups (Meaney and Stewart, 1981b; Olesen et al., 2005; Parent and Meaney, 2008), this difference is often not detected in experiments that test animals in same-sex pairs (e.g., Panksepp and Beatty, 1980; Panksepp, 1981; Thor and Holloway, 1984; Veenema et al., 2013; present results). Thus, as with the traditional sex difference (males $>$ females), the more rapid emergence of play in females may not manifest under all testing conditions. For example, using the mixed-sex testing paradigm, Meaney and Stewart (1981a) found higher levels of play in males compared to females when data were collapsed across 21-25 days of age (onset for each sex, however, was not reported). Nonetheless, we found the "reversed" sex difference in two experiments, even though they were conducted with different experimental protocols (e.g., duration of separation prior to testing, age of playmate, and neutral-testing-cage vs. resident-intruder paradigm). Future studies are needed to determine whether the more rapid development of play in females is restricted to play behavior, or whether it reflects a more general sex difference in overall development.

Early-life experience can also impact later levels of juvenile play in a sex-dependent manner (Parent and Meaney, 2008). Hence, it is possible that the stress of shipping in the second week of life contributed to the earlier emergence of female play, perhaps by selectively decreasing play in males. However, various earlylife manipulations can increase or decrease play of juvenile males (Veenema and Neumann, 2009; Edelmann et al., 2013), or affect both sexes equivalently (Karkow and Lucion, 2013). No studies have directly tested shipping effects on play's emergence.

It is tempting to speculate that inhibitory actions of AVP from the BNST are responsible for slower play development in males. At the end of the third week of life, BNST AVP mRNA is high in males, but virtually undetectable in females (present results; Szot and Dorsa, 1993). Likewise sex differences in AVP immunostaining in the lateral septum are similarly extreme at this age (De Vries et al., 1981). Therefore only males would be subject to this inhibition, and AVP's decline around weaning (present results; Szot and Dorsa, 1993) may facilitate play development in this sex. Szot and Dorsa (1993) reported a similar decline in BNST AVP mRNA at 21 days of age from peak levels occurring around 7-14 days of age. Given that AVP mRNA is tightly regulated by testosterone (Miller et al., 1989, 1992), this transient peak in BNST AVP mRNA is likely the result of activation from the neonatal surge in testosterone that occurs around birth (Szot and Dorsa, 1993 and references therein). Further studies are needed to test whether this sexually dimorphic developmental regulation of BNST AVP has consequences for sex differences in social development, including play's emergence.
While AVP mRNA expression in the BNST correlates negatively with the emergence of play in individual weanling-aged males (present results), prenatal exposure to an immune challenge, lipopolysaccharide (LPS), decreases both play and BNST AVP mRNA of juveniles male rats (Taylor et al., 2012). There are several potential explanations for these seemingly contradictory findings. First, the role of BNST AVP in play behavior may change across age, similar to that found for septal AVP in social recognition in juveniles compared to adults (Veenema et al., 2012). Taylor et al. tested juveniles, whereas we tested weanlings. Perhaps AVP's role differs in the onset vs. maintenance of play. Second, LPS injections might have reduced a stimulatory drive to play, which could have been accompanied by a compensatory reduction in inhibitory mechanisms in the BNST. Collectively, these studies indicate a complex role for AVP in social development that differs by age and sex.

Neurodevelopmental disorders that impact social behavior often show striking sex differences in incidence, progression, and symptom severity (Rutter et al., 2003; Fombonne, 2009; Abel et al., 2010). Understanding the underlying mechanisms that direct social development, particularly those mechanisms that differ between males and females, may explain sex differences in vulnerability to neurodevelopmental disorders (De Vries, 2004). Evidence is now mounting that social and affective disorders involve perturbations in AVP and other neuropeptide systems (e.g., Heinrichs et al., 2009; Harony and Wagner, 2010). The present investigation implicates the PVN and BNST AVP systems in AVP's sexually dimorphic actions on play, hints at a previously unknown sex difference in social development, and suggests that $\mathrm{AVP}$ is a regulating factor in the emergence of play. Findings from multiple studies, including our own, demonstrate that AVP acts in a sex-specific manner during development, as it does in adulthood.

\section{AUTHOR CONTRIBUTIONS}

Matthew J. Paul and Geert J. de Vries designed the study, participated in the behavioral and neuroanatomical analysis, and wrote the first and subsequent drafts of the paper. Matthew J. Paul, Joseph I. Terranova, Clemens K. Probst, Elaine K. Murray, and Nafissa I. Ismail assisted in developing the protocol for, and execution of, behavioral testing and in situ hybridization. All authors discussed the results, contributed to the writing of the paper, and approved its final version.

\section{ACKNOWLEDGMENTS}

We thank Emma Crowley and Victor Zhu for technical assistance; Nancy Forger for helpful comments on the manuscript. The research was supported by NIMH RO1 MH47538 (to Geert J. de Vries).

\section{REFERENCES}

Abel, K. M., Drake, R., and Goldstein, J. M. (2010). Sex differences in schizophrenia. Int. Rev. Psychiatry 22, 417-428. doi: 10.3109/09540261.2010. 515205

Alessandri, S. M. (1992). Attention, play, and social behavior in ADHD preschoolers. J. Abnorm. Child Psychol. 20, 289-302. doi: 10.1007/bf00916693

Bekoff, M., and Byers, J. A. (1998). Animal Play: Evolutionary, Comparative and Ecological Perspectives. Cambridge, UK: Cambridge University Press. 
Bolles, R. C., and Woods, P. J. (1964). The ontogeny of behaviour in the albino rat. Anim. Behav. 12, 427-441. doi: 10.1016/0003-3472(64)90062-4

Caldwell, H. K., Lee, H.-J., Macbeth, A. H., and Young, W. S. (2008). Vasopressin: behavioral roles of an "original" neuropeptide. Prog. Neurobiol. 84, 1-24. doi: 10. 1016/j.pneurobio.2007.10.007

Cheng, S.-Y., and Delville, Y. (2009). Vasopressin facilitates play fighting in juvenile golden hamsters. Physiol. Behav. 98, 242-246. doi: 10.1016/j.physbeh.2009. 04.019

Cheng, S.-Y., Taravosh-Lahn, K., and Delville, Y. (2008). Neural circuitry of play fighting in golden hamsters. Neuroscience 156, 247-256. doi: 10.1016/j. neuroscience.2008.07.048

Dent, G. W., Okimoto, D. K., Smith, M. A., and Levine, S. (2000). Stress-induced alterations in corticotropin-releasing hormone and vasopressin gene expression in the paraventricular nucleus during ontogeny. Neuroendocrinology 71, 333342. doi: 10.1159/000054554

De Souza, M. A., Centenaro, L. A., Menegotto, P. R., Henriques, T. P., Bonini, J., Achaval, M., et al. (2013). Prenatal stress produces social behavior deficits and alters the number of oxytocin and vasopressin neurons in adult rats. Neurochem. Res. 38, 1479-1489. doi: 10.1007/s11064-013-1049-5

De Vries, G. J. (2004). Minireview: sex differences in adult and developing brains: compensation, compensation, compensation. Endocrinology 145, 1063-1068. doi: 10.1210/en.2003-1504

De Vries, G. J., and Buijs, R. M. (1983). The origin of the vasopressinergic and oxytocinergic innervation of the rat brain with special reference to the lateral septum. Brain Res. 273, 307-317. doi: 10.1016/0006-8993(83)90855-7

De Vries, G. J., Buijs, R. M., and Swaab, D. F. (1981). Ontogeny of the vasopressinergic neurons of the suprachiasmatic nucleus and their extrahypothalamic projections in the rat brain-presence of a sex difference in the lateral septum. Brain Res. 218, 67-78. doi: 10.1016/0006-8993(81)90989-6

De Vries, G. J., and Panzica, G. C. (2006). Sexual differentiation of central vasopressin and vasotocin systems in vertebrates: different mechanisms, similar endpoints. Neuroscience 138, 947-955. doi: 10.1016/j.neuroscience.2005. 07.050

Edelmann, M. N., Demers, C. H., and Auger, A. P. (2013). Maternal touch moderates sex differences in juvenile social play behavior. PLoS One 8:e57396. doi: 10.1371/journal.pone.0057396

Fombonne, E. (2009). Epidemiology of pervasive developmental disorders. Pediatr. Res. 65, 591-598. doi: 10.1203/pdr.0b013e31819e7203

Forbes-Lorman, R. M., Rautio, J. J., Kurian, J. R., Auger, A. P., and Auger, C. J. (2012). Neonatal MeCP2 is important for the organization of sex differences in vasopressin expression. Epigenetics 7, 230-238. doi: 10.4161/epi.7.3.19265

Harony, H., and Wagner, S. (2010). The contribution of oxytocin and vasopressin to mammalian social behavior: potential role in autism spectrum disorder. Neurosignals 18, 82-97. doi: 10.1159/000321035

Heinrichs, M., Von Dawans, B., and Domes, G. (2009). Oxytocin, vasopressin, and human social behavior. Front. Neuroendocrinol. 30, 548-557. doi: 10.1016/j. yfrne.2009.05.005

Hol, T., Van den Berg, C. L., Van Ree, J. M., and Spruijt, B. M. (1999). Isolation during the play period in infancy decreases adult social interactions in rats. Behav. Brain Res. 100, 91-97. doi: 10.1016/s0166-4328(98)00116-8

Jones, P., Rodgers, B., Murray, R., and Marmot, M. (1994). Child development risk factors for adult schizophrenia in the British 1946 birth cohort. Lancet 344, 1398-1402. doi: 10.1016/s0140-6736(94)90569-x

Jordan, R. (2003). Social play and autistic spectrum disorders a perspective on theory, implications and educational approaches. Autism 7, 347-360. doi: 10. $1177 / 1362361303007004002$

Karkow, A. R. M., and Lucion, A. B. (2013). Mild environmental intervention in mother-infant interactions reduces social play behavior in rats. Psychol. Neurosci. 6, 39-44. doi: 10.3922/j.psns.2013.1.07

Krebs-Kraft, D. L., Hill, M. N., Hillard, C. J., and McCarthy, M. M. (2010) Sex difference in cell proliferation in developing rat amygdala mediated by endocannabinoids has implications for social behavior. Proc. Natl. Acad. Sci. U S A 107, 20535-20540. doi: 10.1073/pnas.1005003107

Kurian, J. R., Bychowski, M. E., Forbes-Lorman, R. M., Auger, C. J., and Auger, A. P. (2008). Mecp2 organizes juvenile social behavior in a sex-specific manner. J. Neurosci. 28, 7137-7142. doi: 10.1523/jneurosci.1345-08.2008

Meaney, M. J., and Stewart, J. (1981a). A descriptive study of social development in the rat (Rattus norvegicus). Anim. Behav. 29, 34-45. doi: 10.1016/s00033472(81)80149-2
Meaney, M. J., and Stewart, J. (1981b). Neonatal androgens influence the social play of prepubescent rats. Horm. Behav. 15, 197-213. doi: 10.1016/0018$506 x(81) 90028-3$

Miller, M. A., DeVries, G. J., al-Shamma, H. A., and Dorsa, D. M. (1992). Decline of vasopressin immunoreactivity and mRNA levels in the bed nucleus of the stria terminalis following castration. J. Neurosci. 12, 2881-2887.

Miller, M. A., Urban, J. H., and Dorsa, D. M. (1989). Steroid dependency of vasopressin neurons in the bed nucleus of the stria terminalis by in situ hybridization. Endocrinology 125, 2335-2340. doi: 10.1210/endo-125-5-2335

Murakami, G., Hunter, R. G., Fontaine, C., Ribeiro, A., and Pfaff, D. (2011). Relationships among estrogen receptor, oxytocin and vasopressin gene expression and social interaction in male mice. Eur. J. Neurosci. 34, 469-477. doi: 10.1111/j. 1460-9568.2011.07761.x

Newman, S. W. (1999). The medial extended amygdala in male reproductive behavior. A node in the mammalian social behavior network. Ann. N Y Acad. Sci. 877, 242-257. doi: 10.1111/j.1749-6632.1999.tb09271.x

Olesen, K. M., Jessen, H. M., Auger, C. J., and Auger, A. P. (2005). Dopaminergic activation of estrogen receptors in neonatal brain alters progestin receptor expression and juvenile social play behavior. Endocrinology 146, 3705-3712. doi: 10.1210/en.2005-0498

Olioff, M., and Stewart, J. (1978). Sex differences in the play behavior of prepubescent rats. Physiol. Behav. 20, 113-115. doi: 10.1016/0031-9384(78)90060-4

Panksepp, J. (1981). The ontogeny of play in rats. Dev. Psychobiol. 14, 327-332. doi: $10.1002 /$ dev.420140405

Panksepp, J., and Beatty, W. W. (1980). Social deprivation and play in rats. Behav. Neural Biol. 30, 197-206. doi: 10.1016/s0163-1047(80)91077-8

Parent, C. I., and Meaney, M. J. (2008). The influence of natural variations in maternal care on play fighting in the rat. Dev. Psychobiol. 50, 767-776. doi: 10. 1002/dev.20342

Pellegrini, A. D. (1988). Elementary-school children's rough-and-tumble play and social competence. Dev. Psychol. 24, 802-806. doi: 10.1037/0012-1649.24. 6.802

Pellis, S. M., Field, E. F., Smith, L. K., and Pellis, V. C. (1997). Multiple differences in the play fighting of male and female rats. Implications for the causes and functions of play. Neurosci. Biobehav. Rev. 21, 105-120. doi: 10.1016/01497634(95)00060-7

Rutter, M., Caspi, A., and Moffitt, T. E. (2003). Using sex differences in psychopathology to study causal mechanisms: unifying issues and research strategies. J. Child Psychol. Psychiatry 44, 1092-1115. doi: 10.1111/1469-7610. 00194

Sawchenko, P. E., and Swanson, L. W. (1982). Immunohistochemical identification of neurons in the paraventricular nucleus of the hypothalamus that project to the medulla or to the spinal cord in the rat. J. Comp. Neurol. 205, 260-272. doi: $10.1002 /$ cne. 902050306

Szot, P., and Dorsa, D. M. (1993). Differential timing and sexual dimorphism in the expression of the vasopressin gene in the developing rat brain. Brain Res. Dev. Brain Res. 73, 177-183. doi: 10.1016/0165-3806(93)90136-X

Taylor, P. V., Veenema, A. H., Paul, M. J., Bredewold, R., Isaacs, S., and De Vries, G. J. (2012). Sexually dimorphic effects of a prenatal immune challenge on social play and vasopressin expression in juvenile rats. Biol. Sex Differ. 3:15. doi: 10. 1186/2042-6410-3-15

Thiels, E., Alberts, J. R., and Cramer, C. P. (1990). Weaning in rats: II. Pup behavior patterns. Dev. Psychobiol. 23, 495-510. doi: 10.1002/dev.420230605

Thor, D. H., and Holloway, W. R. (1984). Sex and social play in juvenile rats (Rattus norvegicus). J. Comp. Psychol. 98, 276-284. doi: 10.1037/0735-7036.98. 3.276

Van den Berg, C. L., Hol, T., Van Ree, J. M., Spruijt, B. M., Everts, H., and Koolhaas, J. M. (1999). Play is indispensable for an adequate development of coping with social challenges in the rat. Dev. Psychobiol. 34, 129-138. doi: 10.1002/(sici)10982302(199903)34:2<129::aid-dev6>3.3.co;2-c

Vanderschuren, L. J. M. J., Niesink, R. J. M., and Van Pee, J. M. (1997). The neurobiology of social play behavior in rats. Neurosci. Biobehav. Rev. 21, 309326. doi: 10.1016/s0149-7634(96)00020-6

Veenema, A. H., Blume, A., Niederle, D., Buwalda, B., and Neumann, I. D. (2006). Effects of early life stress on adult male aggression and hypothalamic vasopressin and serotonin. Eur. J. Neurosci. 24, 1711-1720. doi: 10.1111/j.1460-9568.2006. 05045.x

Veenema, A. H., Bredewold, R., and De Vries, G. J. (2012). Vasopressin regulates social recognition in juvenile and adult rats of both sexes, but in 
sex- and age-specific ways. Horm. Behav. 61, 50-56. doi: 10.1016/j.yhbeh.2011. 10.002

Veenema, A. H., Bredewold, R., and De Vries, G. J. (2013). Sex-specific modulation of juvenile social play by vasopressin. Psychoneuroendocrinology 38, 2554-2561. doi: 10.1016/j.psyneuen.2013.06.002

Veenema, A. H., and Neumann, I. D. (2009). Maternal separation enhances offensive play-fighting, basal corticosterone and hypothalamic vasopressin mRNA expression in juvenile male rats. Psychoneuroendocrinology 34, 463-467. doi: 10. 1016/j.psyneuen.2008.10.017

Conflict of Interest Statement: The authors declare that the research was conducted in the absence of any commercial or financial relationships that could be construed as a potential conflict of interest.
Received: 23 December 2013; accepted: 11 February 2014; published online: 28 February 2014.

Citation: Paul MJ, Terranova JI, Probst CK, Murray EK, Ismail NI and de Vries GJ (2014) Sexually dimorphic role for vasopressin in the development of social play. Front. Behav. Neurosci. 8:58. doi: 10.3389/fnbeh.2014.00058

This article was submitted to the journal Frontiers in Behavioral Neuroscience.

Copyright $\odot 2014$ Paul, Terranova, Probst, Murray, Ismail and de Vries. This is an open-access article distributed under the terms of the Creative Commons Attribution License (CC BY). The use, distribution or reproduction in other forums is permitted, provided the original author(s) or licensor are credited and that the original publication in this journal is cited, in accordance with accepted academic practice. No use, distribution or reproduction is permitted which does not comply with these terms. 